\title{
Special issue: new insights into soil carbon cycling leveraging networks, synthesis, and long-term studies
}

\author{
Samantha R. Weintraub-Leff $\mathbb{D} \cdot$ - William R. Wieder $(\mathbb{D}$
}

Received: 17 August 2021 / Accepted: 18 August 2021/Published online: 1 September 2021

(C) The Author(s), under exclusive licence to Springer Nature Switzerland AG 2021

Soil carbon (C) plays a critical role in the functioning of ecosystems from local to global scales. Soils contain the largest actively cycling terrestrial $\mathrm{C}$ pool and thus influence Earth's climate. Previous work has documented large losses of soil $\mathrm{C}$ due to historic agricultural practices. At the same time, management for enhanced soil carbon storage may hold promise to help sequester atmospheric $\mathrm{CO}_{2}$ to meet desirable future climate outcomes. Not only does soil carbon influence the global $\mathrm{C}$ cycle and climate dynamics, but it also influences soil physical properties (e.g., hydraulic and thermal function) due to effects on soil infiltration rates, water holding capacity, and thermal conductivity. Moreover, soil $\mathrm{C}$ is a major contributor to soil health through impacts on soil fertility and microbial activity. Indeed, whether in managed or natural landscapes, soil $\mathrm{C}$ is a fundamentally important ecosystem property.

S. R. Weintraub-Leff $(\bowtie)$

National Ecological Observatory Network, Battelle, Boulder, CO 80301, USA

e-mail: sweintraub@battelleecology.org

W. R. Wieder

Institute of Arctic and Alpine Research, University of

Colorado Boulder, Boulder, CO 80309, USA

W. R. Wieder

Climate and Global Dynamics Laboratory, National

Center for Atmospheric Research, Boulder,

CO 80309, USA
The amount and stability of soil $\mathrm{C}$ is regulated by complex physical, chemical and biological processes that interact at multiple spatial and temporal scales. Despite many decades of research and recent exciting conceptual and analytical advances, there is still notable uncertainty in our ability to predict spatiotemporal patterns of soil $\mathrm{C}$ from landscape to regional and global scales, what controls these patterns, and how they may change with altered climate, land use, and other drivers. These gaps may be partially explained by a mismatch of scales. The fundamental controls over soil carbon turnover and persistence rely on microorganisms accessing organic matter in highly heterogeneous soils environments. These encounters must occur under tolerable abiotic conditions and require that microbial organisms, or communities, have the enzymatic capacity to break down and assimilate substrates while gaining enough resources to function, grow, and reproduce. These fine scale controls at any point and time are mediated by multidimensional covariates (e.g., climate, relief, disturbances, etc.), which interact to regulate emergent patterns over space, depth, and time.

Given challenges related to measuring and modeling soil carbon pools, fluxes, and their likely responses to environmental change, there is increasing recognition of the value of long-term, broad-scale data collection and synthesis to uncover biogeochemical dynamics at macrosystem scales. Using a combination 
of long-term ecosystem experiments, multi-site data collection efforts (often via coordinated research networks), synthesis leading to database creation and global data products, plus advanced analytical techniques, 'big data' soils resources can be brought to bear to achieve larger-scale inference and uncover emergent properties of soil $\mathrm{C}$ over broader landscapes and longer timeframes. This special issue highlights several recent efforts on this theme.

Four papers in this collection examine changes in soil $\mathrm{C}$ dynamics over time in the context of changes in inputs, management, or climate. Sayer et al. (2020) investigated the response of soil $\mathrm{C}$ to 13 years of altered litter inputs in a wet tropical forest in Panama. They found that total $\mathrm{C}$ declines more with litter removal than it increases with litter addition, and that surprisingly little particulate $\mathrm{C}$ accumulates even when litter inputs are doubled, likely due to fast rates of cycling and turnover in this humid tropical forest. Stoner et al. (2021) used radiocarbon measurements coupled with a soil model to see how $60+$ years of phosphorus (P) additions plus irrigation influenced soil C in New Zealand pastures. Similarly, they found that total $\mathrm{C}$ stocks did not increase over these decades of management because increased productivity/inputs were offset by increased decomposition and faster turnover rates of both fast and slow cycling pools. Hou et al. (2020) examined changes in soil $\mathrm{C}$ over 25 years in response to annual climate variation plus fire in a New Mexico dryland system. They found that bulk soil $\mathrm{C}$ content is highly sensitive to wet and dry seasonal cycles, with more soil $\mathrm{C}$ in dry periods and less in wet periods, contrary to the dynamics aboveground. Moreover, fire reduced soil $\mathrm{C}$ and it did not recover in over 15 years of monitoring. Scott et al. (2021) assessed the generality of controls on stable soil $\mathrm{C}$ accumulation with several decades of restoration of cultivated lands to grasslands in the US and South Africa. They found that stable C always increased with time, but that the importance of microbes, roots, and soil structure varied by region and may be linked to differences in site climate and texture. Together, these papers highlight the importance of long-term monitoring for new insights into soil C stability and change.

Several other papers seek to expand the spatial scale over which data are collected through innovative techniques and extensive research networks. Sanderman et al. (2021) used spectroscopy and machine learning with data from two continents to infer and map depth-resolved soil $\mathrm{C}$ fractions across the Great Plains region of the United States. These spectroscopic approaches offer exciting ways to expand beyond traditional fractionation methods to rapidly generate datasets that can be used to inform mapping, models, and management decisions. Looking at soil profiles collected across the National Ecological Observatory Network (NEON) Heckman et al. (2020) ask if the same soil properties that correlate with soil C concentrations are also responsible for conferring $\mathrm{C}$ persistence, as estimated by radiocarbon measurements. Contrary to expectations, they did not find evidence that the concentration of metal oxides or exchangeable cations, which tend to correlate with soil $\mathrm{C}$ concentrations, explained any of the variation in soil carbon persistence across ecosystems. Both the Sanderman and Heckman studies look at broad scale patterns of soil $\mathrm{C}$ characteristics, going beyond bulk measurements and including the vast and poorly understood reservoir of carbon at depth in soils.

Recognizing that interdependent, cross-scale interactions determine macrosystem patterns of soil $\mathrm{C}$ distributions, vulnerability, and persistence, Bradford et al. (2021) review evidence that climate history shapes the functional traits of local decomposer communities, potentially mediating soil $\mathrm{C}$ dynamics and their response to environmental change. They argue that measurements, statistical analyses, and numeric models need to de-emphasize capturing the mean state of aggregated data, and instead focus on understanding multi-causal drivers of variance within and among ecosystems. In a separate study, Nave et al. (2021) illustrate how this can be done using a wealth of replicated data collected across NEON sites. Notably, their paper highlights that within-site replication reveals deeper insights into controls over soil C stocks that are obscured when looking at aggregated measurements among sites that span continental-scale gradients. Another example of how historical tendencies to focus on aggregated data can lead to a mismatch between the causal drivers of soil $\mathrm{C}$ stocks in measurements and models is demonstrated by Georgiou et al. (2021). They examined underlying assumptions made by three different soil biogeochemical models, confronting them with machine learning algorithms using globally-distributed soil profile data and gridded soil maps. They found that local-scale soil properties, estimated by soil texture, describe a 
significant amount of the spatial variation in soil $\mathrm{C}$ stocks, but modeled soil C stocks are strongly (and erroneously) related to temperature and plant productivity. These papers emphasize the need to coordinate large-scale research and monitoring activities with modeling efforts to fully leverage new insights into the biogeochemical dynamics of the world beneath our feet.

The papers presented here reflect exciting insights into the controls on soil $\mathrm{C}$ pools and fluxes over larger spatial and temporal scales. Several themes emerged, including a decoupling of inputs from stocks (often assumed to be strong in models), high climate sensitivity in drylands, and the value in embracing the true complexity and heterogeneity of soils, in models as well as measurements. Papers in this special issue also illustrate that soil biogeochemistry is entering an era when large, coordinated measurements taken across multiple ecosystems over long periods of time are able to generate the datasets that allow us to start building more refined knowledge and understanding of the multi-scale controls over soil carbon stocks and fluxes. We are still at the outset and many knowledge gaps remain; all of the papers included here highlight challenges and opportunities for future research. We believe there is an important role for FAIR data principles (Findable, Accessible, Interoperable, Reusable) in this new era of long-term, largescale soil data. Alongside improvements in data sharing and interoperability, continued efforts at coordinated data collection, new theoretical advances, integration among empiricists and modelers, and inclusive team science are needed to ensure we leverage soil $\mathrm{C}$ data for maximal insights, now and in the future.

\section{References}

Bradford MA, Wood SA, Addicott ET et al (2021) Quantifying microbial control of soil organic matter dynamics at macrosystem scales. Biogeochemistry. https://doi.org/10. 1007/s10533-021-00789-5

Georgiou K, Malhotra A, Wieder WR et al (2021) Divergent controls of soil organic carbon between observations and process-based models. Biogeochemistry. https://doi.org/ 10.1007/s10533-021-00819-2

Heckman KA, Nave LE, Bowman M et al (2020) Divergent controls on carbon concentration and persistence between forests and grasslands of the conterminous US. Biogeochemistry. https://doi.org/10.1007/s10533-020-00725-Z

Hou E, Rudgers JA, Collins SL et al (2020) Sensitivity of soil organic matter to climate and fire in a desert grassland. Biogeochemistry. https://doi.org/10.1007/s10533-02000713-3

Nave LE, Bowman M, Gallo A et al (2021) Patterns and predictors of soil organic carbon storage across a continentalscale network. Biogeochemistry. https://doi.org/10.1007/ s10533-020-00745-9

Sanderman J, Baldock JA, Dangal SRS et al (2021) Soil organic carbon fractions in the Great Plains of the United States: an application of mid-infrared spectroscopy. Biogeochemistry. https://doi.org/10.1007/s10533-021-00755-1

Sayer EJ, Baxendale C, Birkett AJ et al (2020) Altered litter inputs modify carbon and nitrogen storage in soil organic matter in a lowland tropical forest. Biogeochemistry. https://doi.org/10.1007/s10533-020-00747-7

Scott DA, Bach EM, Du Preez CC et al (2021) Mechanisms influencing physically sequestered soil carbon in temperate restored grasslands in South Africa and North America. Biogeochemistry. https://doi.org/10.1007/s10533-02100774-y

Stoner SW, Hoyt AM, Trumbore S, Sierra CA et al (2021) Soil organic matter turnover rates increase to match increased inputs in grazed grasslands. Biogeochemistry. https://doi. org/10.1007/s10533-021-00838-z

Publisher's Note Springer Nature remains neutral with regard to jurisdictional claims in published maps and institutional affiliations. 